\title{
Genome sequencing of linezolid-resistant Streptococcus pneumoniae mutants reveals novel mechanisms of resistance
}

\author{
Jie Feng, ${ }^{1,2}$ Andréanne Lupien, ${ }^{1,2}$ Hélène Gingras, ${ }^{1,2}$ Jessica Wasserscheid, ${ }^{3}$ Ken Dewar, ${ }^{3}$ \\ Danielle Légaré, ${ }^{1,2}$ and Marc Ouellette ${ }^{1,2,4}$ \\ ${ }^{1}$ Centre de Recherche en Infectiologie, Québec G1V 4G2, Canada; ${ }^{2}$ Division de Microbiologie, Université Laval, Québec G1V 4G2, \\ Canada; ${ }^{3}$ McGill University and Génome Québec Innovation Centre, Montréal, Québec H3A 1A4, Canada
}

\begin{abstract}
Linezolid is a member of a novel class of antibiotics, with resistance already being reported. We used whole-genome sequencing on three independent Streptococcus pneumoniae strains made resistant to linezolid in vitro in a step-by-step fashion. Analysis of the genome assemblies revealed mutations in the 23S rRNA gene in all mutants including, notably, G2576T, a previously recognized resistance mutation. Mutations in an additional 31 genes were also found in at least one of the three sequenced genomes. We concentrated on three new mutations that were found in at least two independent mutants. All three mutations were experimentally confirmed to be involved in antibiotic resistance. Mutations upstream of the $A B C$ transporter genes spr1021 and spr1887 were correlated with increased expression of these genes and neighboring genes of the same operon. Gene inactivation supported a role for these $A B C$ transporters in resistance to linezolid and other antibiotics. The hypothetical protein spr0333 contains an RNA methyltransferase domain, and mutations within that domain were found in all S. pneumoniae linezolid-resistant strains. Primer extension experiments indicated that spr0333 methylates G2445 of the 23S rRNA and mutations in spr0333 abolished this methylation. Reintroduction of a nonmutated version of spr0333 in resistant bacteria reestablished G2445 methylation and led to cells being more sensitive to linezolid and other antibiotics. Interestingly, the spr0333 ortholog was also mutated in a linezolid-resistant clinical Staphylococcus aureus isolate. Whole-genome sequencing and comparative analyses of $S$. pneumoniae resistant isolates was useful for discovering novel resistance mutations.
\end{abstract}

[Supplemental material is available online at www.genome.org. The sequence data from this study have been submitted to GenBank under accession nos. ABZC00000000 and ABZT00000000.]

Linezolid contains an oxazolidinone ring and represents a novel class of synthetic antibiotics. Linezolid is highly effective against a number of clinically important gram-positive pathogens such as Staphylococcus aureus and its methicillin-resistant version (MRSA), Streptococcus pneumoniae, enterococci, and their vancomycinresistant versions (VRE), and several others (for review, see Vara Prasad 2007). Linezolid binds to the 50S subunit of the bacterial ribosome via interactions with the central loop segment of domain $\mathrm{V}$ of the $23 \mathrm{~S}$ rRNA to block the formation of protein synthesis initiation complexes. Recent cross-linking experiments have shown that oxazolidinone antibiotics interact with the A site of the bacterial ribosome and possibly interfere with the placement of the aminoacyl-tRNA (Leach et al. 2007). This has been further substantiated by the crystal structure of linezolid bound to the 50S ribosome subunit, where the antibiotic was suggested to perturb the correct positioning of tRNAs on the ribosome (Wilson et al. 2008).

S. pneumoniae is the most common human respiratory pathogen, causing mainly pneumonia, acute otitis media, and bacterial meningitis. This pathogen is also frequently involved in lifethreatening infections that are being further aggravated by the appearance and spread of drug-resistance to several classes of antimicrobial agents. For example, a recent survey of U.S. isolates indicated that $25 \%$ of $S$. pneumoniae were resistant to at least two

\footnotetext{
${ }^{4}$ Corresponding author.
}

E-mail Marc.Ouellette@crchul.ulaval.ca; fax (418) 654-2715.

Article published online before print. Article and publication date are at http://www.genome.org/cgi/doi/10.1101/gr.089342.108. antibiotics, and a third of these isolates were resistant to at least four antibiotics (Thornsberry et al. 2008), but all studies confirmed that linezolid is still very active against $S$. pneumoniae (Jones et al. 2007). However, it was shown that linezolid-resistant strains (minimal inhibitory concentration $[\mathrm{MIC}] \geq 8 \mu \mathrm{g} / \mathrm{mL}$ ) of $S$. pneumoniae can be generated in vitro (Carsenti-Dellamonica et al. 2005), that clinical $S$. pneumoniae strains not susceptible to linezolid (MIC $\geq 4 \mu \mathrm{g} / \mathrm{mL}$ ) have been reported (Wolter et al. 2005), and that one resistant clinical isolate of Streptococcus oralis has been described (Mutnick et al. 2003). With the use of linezolid steadily increasing in the Western world, the potential for an increase in resistance to linezolid is likely to be inevitable.

Resistance to linezolid was described in the enterococci (Prystowsky et al. 2001) and the staphylococci (Tsiodras et al. 2001) and is usually due to point mutations in key genes. It was first studied in gram-positive pathogens selected for resistance in vitro, and mutations were noted in domain $\mathrm{V}$ of the $23 \mathrm{~S}$ rRNA. Several mutations have been pinpointed in the $23 \mathrm{~S}$ rRNA, but the most common mutation is G2576T when using the Escherichia coli numbering system (for review, see Meka and Gold 2004). The same mutations were also observed in clinical isolates of $S$. aureus (Tsiodras et al. 2001; Meka et al. 2004), Staphylococcus epidermidis (Hong et al. 2007; Kelly et al. 2008), and in enterococci (Gonzales et al. 2001; Sinclair et al. 2003; Bourgeois-Nicolaos et al. 2007) resistant to linezolid. There are four to six copies of the $23 \mathrm{~S}$ rRNA genes in most gram-positive pathogens, and the level of resistance generally correlates with the number of mutated copies of $23 \mathrm{~S}$ rRNA, as shown in the enterococci (Marshall et al. 2002; Ruggero 
et al. 2003) and in the staphylococci (Tsakris et al. 2007; Besier et al. 2008). Domain V of the $23 \mathrm{~S}$ rRNA is also the binding site of other antibiotics such as chloramphenicol, and linezolid-resistant bacteria are consequently often cross-resistant to these other classes of antibiotics.

In addition to mutations in the 23S rRNA, a 6-bp deletion in the ribosomal protein $\mathrm{L} 4$ has been described in two clinical isolates of $S$. pneumoniae that were resistant to chloramphenicol and not susceptible to linezolid (Wolter et al. 2005). Recently, an integrated plasmid 23S rRNA methyltransferase coded by the $c f r$ gene (for chloramphenicol-florfenicol resistance) was shown to confer resistance to linezolid in S. aureus (Toh et al. 2007; Mendes et al. 2008). There are also other linezolid-resistant strains (selected in vitro or clinical isolates) that do not seem to carry any of the main known mutations (Sander et al. 2002; Carsenti-Dellamonica et al. 2005; Richter et al. 2007); thus, it is possible that other mutations or the acquisition of additional genes may also contribute to linezolid resistance. Recently, with the emergence of new genome analysis technologies such as comparative genome sequencing (CGS) and massively parallel DNA sequencing techniques, whole-genome sequencing has become a powerful method to detect mutations linked to drug resistance or mode of action of antibiotics (Albert et al. 2005; Andries et al. 2005; Manjunatha et al. 2006; Mwangi et al. 2007). We report the use of whole-genome sequencing of three $S$. pneumoniae strains selected independently for in vitro linezolid resistance in a step-by-step fashion to find known (23S rRNA) and novel (RNA methyltransferase, $\mathrm{ABC}$ proteins) genes involved in resistance to this novel drug.

\section{Results}

\section{Generation of mutants and cross-resistance}

Two independent mutants for each of two $S$. pneumoniae strains (R6 and CCRI 1974) were generated by iterative selection for linezolid resistance in vitro. Cells were selected for progressive resistance to $1,2,4,8,16$, and then $32 \mu \mathrm{g} / \mathrm{mL}$ of linezolid. The MICs of the progenitor-susceptible isolates were $0.5 \mu \mathrm{g} / \mathrm{mL}$ for R6 and $0.75 \mu \mathrm{g} / \mathrm{mL}$ for CCRI 1974. The MICs of the most highly resistant isolates were $32 \mu \mathrm{g} / \mathrm{mL}$ and were named R6M1 and R6M2 when derived from S. pneumoniae R6, and CCRI 1974M1 and 1974M2 when derived from S. pneumoniae CCRI 1974. These linezolid-resistant isolates were cross-resistant to chloramphenicol and florfenicol (Table 1), which are antibiotics that also target the $23 \mathrm{~S}$ rRNA. The mutants were not cross-resistant to vancomycin or to erythromycin (Table 1). Vancomycin does not target the $23 \mathrm{~S}$

Table 1. Susceptibility levels of S. pneumoniae isolates

\begin{tabular}{lccccc}
\hline & \multicolumn{5}{c}{ MIC $(\boldsymbol{\mu g} / \mathrm{mL})$} \\
\cline { 2 - 6 } $\begin{array}{l}\text { S. pneumoniae } \\
\text { strains }\end{array}$ & LZD & CHL & FFC & ERY & VAN \\
\hline R6 WT & 0.5 & 3 & 1.6 & 0.064 & 0.38 \\
R6M1 & 32 & 24 & 6 & 0.064 & 0.38 \\
R6M2 & 32 & 32 & 12 & 0.047 & 0.38 \\
$1974 \mathrm{WT}$ & 0.75 & 3 & 3.2 & 0.064 & 0.5 \\
$1974 \mathrm{M} 1$ & 32 & 24 & 12 & 0.047 & 0.5 \\
$1974 \mathrm{M} 2$ & 32 & 24 & 20 & 0.047 & 0.38 \\
\hline
\end{tabular}

Average of at least three independent measures. (WT) Wild-type; (LZD) linezolid; (CHL) chloramphenicol; (FFC) florfenicol; (ERY) erythromycin; (VAN) vancomycin.
rRNA, and while erythromycin does interact with the 23S rRNA within the peptidyl transferase center, it is at a distinct site from linezolid (Schlunzen et al. 2001).

\section{Whole-genome sequencing of S. pneumoniae linezolid-resistant strains}

The two independent R6 mutants R6M1 and R6M2 were resequenced using the comparative genome sequencing (CGS) method developed by NimbleGen (http://www.nimblegen.com/). The CGS technique uses tiled DNA microarray hybridizations and rapidly surveys entire microbial genomes, identifying the locations of SNPs, insertions, or deletions. The mutations are further characterized by a subsequent step of array sequencing. These mutations were then confirmed by PCR sequencing of the regions suspected to be mutated. Both highly resistant R6 mutants R6M1 and R6M2 had a point mutation in each of their four 23S rRNA gene copies at position G2576T (Table 2). In addition to the 23S rRNA gene, CGS pinpointed nine additional mutations in the highly resistant mutant R6M1 and 10 additional mutations in R6M2 (Table 2). Six mutations in R6M1 were located in coding regions and were nonsynonymous. A single synonymous mutation (spr0525) and two deletions causing frameshifts were observed in the genes coding for hypothetical protein spr0333 and the ribosomal large subunit pseudouridine synthase D (spr1824) (Table 2). Nonsynonymous mutations in coding sequences were also the most prevalent in R6M2. Interestingly, two of these mutations were in the same open reading frame coding for the $\mathrm{ABC}$ protein spr1887. The only mutation found in noncoding sequences was also found 46 bp upstream of the spr1887 ATG (Table 2). A nonsense mutation in the argininosuccinate synthase gene spr0102 was detected by CGS in R6M2 (Table 2). Only two mutations were found in common between R6M1 and R6M2, which were the $23 \mathrm{~S}$ rRNA gene copies and hypothetical protein spr0333. To extend this analysis and to test for the putative recurrence of resistance mutations to eventually find novel resistance mutations, we sequenced an independent linezolidresistant isolate derived from the clinical isolate CCRI 1974. By multilocus sequence typing (MLST) analysis (see Methods), it was determined that 1974 was of the sequence type "124" while R6's sequence type was "595." Genome-wide assessments of SNPs as a marker of genetic diversity also confirmed that 1974 and R6 were different (see below).

Since the sequence of wild-type $S$. pneumoniae 1974 was not known, it was not possible to use the NimbleGen CGS technique. We instead used the massively parallel 454 Life Sciences (Roche) GS-FLX DNA sequencing platform to generate a $20 \times$ sequence coverage genome assembly for both the wild-type CCRI 1974 progenitor and the $1974 \mathrm{M} 2$ isolate. The draft genome assemblies are available at NCBI/DDBJ/EMBL/GenBank under the project accession numbers ABZC00000000 and ABZT00000000. A genomewide alignment between R6 and 1974 indicated that the overall genome colinearity has been disrupted by a dispersed set of 18 insertions/deletions representing 4.2\% of the CCRI 1974 genome. We used candidate SNPs as a further surrogate for divergence, and the CCRI 1974 strain genome assembly alignment comparisons generated 11,000 to 15,000 candidate SNPs when compared with R6, TIGR4, or other $S$. pneumoniae strains recently sequenced (Hiller et al. 2007). This number is similar to the 13,000 SNPs that we have measured between the R6 and TIGR4 genomes.

Comparative sequence analysis of $1974 \mathrm{M} 2$ and its sensitive parent revealed 25 mutations that were confirmed by PCR 
Table 2. List of mutations found in S. pneumoniae isolates selected for linezolid resistance

\begin{tabular}{|c|c|c|c|c|c|}
\hline \multirow[b]{2}{*}{ Name of gene } & \multirow[b]{2}{*}{ Locus name $\mathrm{R}^{\mathrm{a}}$} & \multicolumn{4}{|c|}{ S. pneumoniae strains } \\
\hline & & R6M1 & R6M2 & 1974M2 & $1974 \mathrm{M} 1^{\mathrm{b}}$ \\
\hline $23 \mathrm{~S} \mathrm{rDNA}$ & spr_rrnaD23S & G2576T & G2576T & T1743T A2503G & G2576T \\
\hline 235 rDNA & spr_rrnaC23S & G2576T & G2576T & A1743T A2503G & G2576T \\
\hline 235 rDNA & spr_rrnaB23S & G2576T & G2576T & A1743T A2503G & G2576G \\
\hline $23 \mathrm{~S} \mathrm{rDNA}$ & spr_rrnaA23S & G2576T & G2576T & A1743T A2503G & G2576T \\
\hline Hypothetical protein & spro3333 & 282-288 deletion & G623A C208Yc & G626T G209V & G503T S168 \\
\hline$A B C$ transporter, protein & spr1021 & & & $\mathrm{G}-29 \mathrm{~T}^{\mathrm{d}}$ & $\mathrm{G}-29 \mathrm{~T}^{\mathrm{d}}$ \\
\hline$A B C$ transporter, protein & spr1021 & & & C1419G H473Q & \\
\hline$A B C$ transporter, protein & spr1887 & & $G-46 T^{d}$ & $\mathrm{G}-46 \mathrm{~T}^{\mathrm{d}}$ & $\mathrm{G}-32 \mathrm{~T}^{\mathrm{d}}$ \\
\hline$A B C$ transporter, protein & spr1887 & & $\begin{array}{l}\text { G593A G198D } \\
\text { G498T L166F }\end{array}$ & & \\
\hline Acyl-carrier-protein S-malonyltransferase & spr0380 & G896T S297I & & & \\
\hline$A B C$ transporter, protein & spr0525 & C234T R78R & & & \\
\hline Phosphoenolpyruvate carboxylase & spr0947 & A406C T136P & & & \\
\hline Glycosyltransferase & spr0981 & G347A G116E & & & \\
\hline Hypothetical protein & spr1130 & G1562A R521H & & & \\
\hline Phosphoglucosamine mutase & spr1417 & G887C R296P & & & \\
\hline Aspartate aminotransferase & spr1808 & A806G N269S & & & \\
\hline $\begin{array}{l}\text { Ribosomal large subunit pseudouridine } \\
\text { synthase D }\end{array}$ & spr1824 & C208 deletion & & & \\
\hline Argininosuccinate synthase & spr0102 & & G116A W39stop & & \\
\hline $\begin{array}{l}\text { Phosphotransferase system sugar-specific } \\
\text { Ell component }\end{array}$ & spr0421 & & C113A P38H & & \\
\hline$A B C$ transporter, protein & spr1121 & & G514T D172Y & & \\
\hline Hypothetical protein & spr1195 & & G921A M307I & & \\
\hline Hypothetical protein & spr1316 & & G337A E113K & & \\
\hline Hypothetical protein & spr1465 & & C317T P106L & & \\
\hline Magnesium transporter & spr0170 & & & $G-3 T^{d}$ & \\
\hline Competence-induced protein Ccs 4 & spr0182 & & & T1380G N460K & \\
\hline 50 S ribosomal protein $L 4$ & spr0189 & & & G211A G71R & \\
\hline Single-strand-DNA-specific exonuclease Rec] & spr0537 & & & C1400T T467M & \\
\hline Elongation factor Tu family protein & spr0598 & & & $A-52 C^{d}$ & \\
\hline Spermidine synthase & spr0819 & & & G146T G49V & \\
\hline Translation initiation factor IF-3 & spr0861 & & & C454A H152N & \\
\hline Hypothetical protein & spr1236 & & & C277T Q93stop & \\
\hline Putative oxidoreductase & spr1325 & & & A393C E131D & \\
\hline$A B C$ transporter, substrate-binding protein & spr1534 & & & C50A A17D & \\
\hline Sialidase A precursor & spr1536 & & & G430T D144Y & \\
\hline Sucrose operon repressor & spr1569 & & & G191T G64V & \\
\hline Capsular polysaccharide biosynthesis protein & spr1654 & & & C1032A H344Q & \\
\hline Xanthine phosphoribosyltransferase & spr1662 & & & $C-216 A^{d}$ & \\
\hline
\end{tabular}

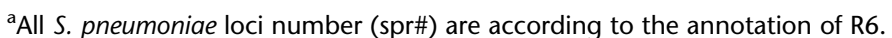

${ }^{\mathrm{b}}$ The genome of this mutant was not sequenced. Only the genes found mutated in 1974M2 were PCR amplified and sequenced in $1974 \mathrm{M} 1$.

'When the mutations are within coding regions, the change in amino acids is also indicated in italics.

dIn noncoding sequence. The number preceded by "-" indicates the position upstream of the ATG.

amplification and conventional DNA sequencing. Sequence analysis highlighted mutations in the 23S rRNA genes of 1974M2, although they differed from the two R6 mutants, with mutations at position 1743 for three out of four 23S rRNA gene copies and at position 2503 for the four copies (Table 2). Eighteen additional mutations were found and confirmed in 1974M2 when compared with the wild-type sequence. Five of the 18 mutations were in noncoding regions. Interestingly, the same mutation ( $\mathrm{G}$ to $\mathrm{T}$ ) 46 bp upstream of the ABC gene spr1887 found in R6M2 was also present in 1974M2 (Table 2). The 13 other mutations were in coding regions, with 12 nonsynonymous substitutions and one nonsense mutation. The hypothetical protein spr0333 mutated in both R6 mutants was also mutated in 1974M2 (Table 2). We also PCR amplified and sequenced all the genes that were found to be mutated in 1974M2 in the independent mutant 1974M1. We found that the 23S rRNA gene was mutated in 1974M1 at the G2576T position in three of the four $23 \mathrm{~S}$ rRNA gene copies (Table 2). Mutations in three additional genes (not necessarily at the same position as in 1974M2) were common between 1974M1 and
1974M2. One was in the coding region of the hypothetical protein spr0333, and the two other mutations were upstream of two operons, each encoding for ABC proteins (spr1021 and spr1887) (Table 2).

\section{Mutations in known loci associated with linezolid resistance}

The sequencing of three independent linezolid-resistant mutants and PCR analysis of targeted regions of a fourth mutant (1974M1) highlighted mutations in two genes already linked to linezolid resistance but also in 27 genes never previously associated with resistance. In the category of known mutations, the G2576 position within the domain $\mathrm{V}$ region of the $23 \mathrm{~S}$ rRNA is central to linezolid resistance. In staphylococci and enterococci, the number of mutated copies of the 23S rRNA is generally correlated with linezolid MIC (see above), and this correlation was generally true for the four $S$. pneumoniae isolates studied in this report. In the R6M1 and R6M2 mutants, three copies of the 23S rRNA were mutated at position 2576 in cells with a MIC of $2 \mu \mathrm{g} / \mathrm{mL}$, and

\section{Genome Research www.genome.org}


the fourth copy was mutated in cells resistant to $4 \mu \mathrm{g} / \mathrm{mL}$ of linezolid (Supplemental Table 2). Three copies were also mutated at the same position in 1974M1 with a MIC of $2 \mu \mathrm{g} / \mathrm{mL}$, but the fourth copy remained nonmutated even in the most resistant cells (Supplemental Table 2). The position G2576 was not mutated in 1974M2. Instead, positions 1743 and 2503 were mutated and three copies of the domain V 235 rRNA had the A2503G mutation at $16 \mu \mathrm{g} / \mathrm{mL}$, while the fourth copy was mutated when cells reached a MIC of $32 \mu \mathrm{g} / \mathrm{mL}$ (Supplemental Table 2).

Small deletions in the 50S ribosomal protein L4 were observed in clinical strains of $S$. pneumoniae with decreased susceptibility to linezolid (Wolter et al. 2005). It is salient to point out that in mutant $1974 \mathrm{M} 2$, whole-genome sequencing revealed that the L4 protein is mutated to G71R, a conserved region of L4.

\section{$A B C$ transporters and linezolid resistance}

In addition to the known loci associated previously with linezolid resistance, we found 31 additional genes that were mutated in at least one of the three resistant strains that were sequenced. As an initial strategy to confirm the role of these novel mutations in resistance, we concentrated on genes that were mutated in at least two independent mutants. We reasoned that a recurrent mutation may increase the likelihood that it is associated with resistance, whereas a unique mutation may simply be a random replication error due to stress. Members of the ABC proteins can act as drug efflux pumps in some organisms (Ouellette et al. 1994), and five $\mathrm{ABC}$ protein genes were mutated in the linezolid-resistant mutants. This included spr0525 in R6M1, spr1534 in 1974M2, and spr1121 in R6M2. However, mutations in both the upstream and coding regions of two ABC protein genes, spr1021 and spr1887, were noted in three of the four linezolid-resistant isolates studied (Table 2). Consistent with our strategy of recurrent mutations, we attempted to assess the role of the latter two $\mathrm{ABC}$ genes in linezolid resistance. The mutations upstream of these two genes occurred early during the selection process in both 1974M2 and R6M2 but later in 1974M1 (Supplemental Table 2). Both genes are part of predicted operons (Fig. 1), and we used qRT-PCR to test whether a correlation existed between the mutation upstream of these operons and their expression. The $\mathrm{ABC}$ spr1021 gene is part of a three-gene operon (Fig. 1A), and the expression of the three genes was found to be increased seven- to 13-fold in the 1974M1 and 1974M2 mutants (Fig. 1A). The expression of these genes was not altered in the R6M2 that had no mutation upstream of this operon (Fig. 1A). The genes spr1020 and spr1024 were not overexpressed in 1974M2 (Fig. 1A), indicating that they are not part of the same operon as spr1021.

$\mathrm{G}$ to $\mathrm{T}$ transversions were found either at position 32 or 46 upstream of the operon containing spr1887. We similarly tested by qRT-PCR whether these mutations were correlated with increased expression of these genes. This was indeed the case, with a seven- to 13 -fold increase in expression (Fig. 1B). The spr1884 and spr1888 genes were not overexpressed as determined by qRTPCR (Fig. 1B).

The increased expression of these $\mathrm{ABC}$ protein genes may be linked to resistance, but since they are co-overexpressed with other genes, we assessed the role in resistance of each of these genes by gene inactivation in S. pneumoniae. The three genes of the spr1021 operon (spr1021, an ABC protein; spr1022, a putative transcriptional regulator; spr1023, a putative transmembrane protein) were individually inactivated by insertional duplication mutagenesis using the nonreplicative plasmid pFF6 (Supplemental Table 1) containing a kanamycin resistance marker. Inactivation of the three genes in the wild-type background did not lead to any changes in susceptibility to linezolid (results not shown). However, when the three genes were inactivated independently in S. pneumoniae 1974M2, a phenotype of a threefold decrease in linezolid resistance was found in cells in which spr1021 was inactivated (Table 3). No phenotype was observed in 1974M2 in which spr1022 or spr1023 was inactivated (not shown). Interestingly, cells in which spr1021 was inactivated not only were more susceptible to linezolid but also were less cross-resistant to chloramphenicol and florfenicol (Table 3). We have attempted to overproduce spr1021 (wild-type or mutated versions) in wild-type cells. Resistance was minimal and not significant when compared with controls (results not shown).

The spr1887 gene is part of an operon containing two $\mathrm{ABC}$ protein genes (spr1885 and spr1887). These $\mathrm{ABC}$ proteins, also known as PatA and PatB, have been linked to resistance to a number of drugs, including fluoroquinolones (Marrer et al. 2006b). This prompted us to test and subsequently verify that both the $1974 \mathrm{M} 1$ and 1974M2 mutants, with increased patA and patB expression (Fig. 1), were also cross-resistant to ciprofloxacin (Table $3)$. We inactivated both genes in both the CCRI1974 and in the 1974M2 background. In the wild-type background, we failed to show a decrease in susceptibility to linezolid (results not shown). However, a small but reproducible decrease in linezolid resistance was observed when any of the two genes was inactivated in the 1974M2 background (Table 3). Interestingly, resistance to several other drugs targeting the 23S rRNA was decreased significantly when either spr1887 or spr1885 were inactivated in 1974M2 (Table 3). Consistent with the known role of PatA and PatB in ciprofloxacin resistance of transcription initiation (arrows) and termination (vertical bars) of the operons are indicated. Values represent an average of three independent experiments. 
Table 3. Functional analysis of $S$. pneumoniae genes in antibiotic resistance

\begin{tabular}{lccccl}
\hline & & \multicolumn{5}{c}{ MIC $(\boldsymbol{\mu g} / \mathrm{mL})$} \\
\cline { 3 - 6 } $\begin{array}{l}\text { S. pneumoniae } \\
\text { strains }\end{array}$ & Plasmid & LZD & CHL & FFC & CIP \\
\hline 1974WT & - & 0.75 & 3 & 3 & 0.25 \\
$1974 \mathrm{M} 2$ & - & 32 & 24 & 20 & 2 \\
$1974 \mathrm{M} 2$ & pJF_1021KO & 12 & 12 & 8 & 1 \\
$1974 \mathrm{M} 2$ & pJF_1887KO & 20 & 6 & 8 & 0.25 \\
$1974 \mathrm{M} 2$ & pJF_1885KO & 24 & 8 & 8 & 0.38 \\
$1974 \mathrm{M1}$ & pDL289 & 32 & 24 & 12 & 1.5 \\
$1974 \mathrm{M1}$ & pJF_0333 & 12 & 12 & 6 & 1.5 \\
R6 WT & - & 0.5 & 3 & 1.6 & 0.38 \\
R6 WT & pJF_0333KO & 0.5 & - & - & - \\
R6 M1 & pDL289 & 32 & - & - & - \\
R6 M1 & pJF_0333 & 16 & - & - & - \\
\hline
\end{tabular}

Average of at least three independent measures. (LZD) linezolid; (CHL) chloramphenicol; (FFC) florfenicol; (CIP) ciprofloxacin; (KO) knock-out construct.

(Marrer et al. 2006b), inactivation of either of these ABC genes led to a 10-fold decrease in ciprofloxacin resistance back to wild-type levels (Table 3).

\section{RNA methyltransferase and linezolid resistance}

Other than genes corresponding to the 23S rRNA, only one other gene was mutated in all four mutants, which corresponded to the hypothetical protein spr0333 (Table 2). Further analysis revealed that spr0333 corresponded to a protein of 385 amino acids containing PFAM domains for S-adenosylmethionine (SAM)-dependent methyltransferases (PFAM UPF0020). The spr0333 protein exhibited $32 \%$ sequence identity with a domain of the 702-aminoacid E. coli gene product YcbY, which encodes an RNA methyltransferase responsible for the $N^{2}$-methylation of G2445 in the 23S rRNA (Lesnyak et al. 2006). Orthologs of spr0333 were found in many bacterial species, including several pathogens (Fig. 2). Mutations in spr0333 were at different positions and included nonsynonymous mutations and a frameshift deletion (Table 2), but all were in the conserved SAM-methyltransferase domain. These mutations may render spr0333 inactive and may be linked to linezolid resistance. Methylation of ribosomal RNA is a frequent mechanism of acquired resistance to antibiotics such as erythromycin (for review, see Roberts 2008). It has recently been argued that one role of endogenous RNA methylases may be in 23S rRNA protection against natural xenobiotics (Toh and Mankin 2008). Therefore, we tested by primer extension whether spr0333 had 23S rRNA methylation activity, and in particular whether residue G2445 (E. coli numbering) was modified to $\mathrm{m}^{2} \mathrm{G}$ in the $23 \mathrm{~S}$ rRNA of $S$. pneumoniae. $N^{2}$-methylguanosine blocks AMV reverse transcriptase during primer extension experiments, thus causing a stop one nucleotide before the modified guanosine. A reverse transcription stop was observed at position G2445 when the 23S rRNA template was extracted from the wild-type cells CCRI1974 (Fig. 3B, lane 1). Mutant 1974M1 had a point mutation leading to a mutated spr0333 protein with S168I (Table 2). When the 23S rRNA was derived from 1974M1 and used as a template in reverse transcription reactions, we did not observe a stop at position 2445 (Fig. 3B, lane 2). To ascertain that the lack of methylation as measured by primer extension was due to a mutated version of spr0333, we transformed pJF0333 (the spr0333 gene cloned into a shuttle vector replicating in $S$. pneumoniae, Supplemental Table 1) in the strain 1974M1. When the mutant was transformed with the empty vector, we still did not observe a stop at position 2445 (Fig. 3, lane 4), but in mutant cells transformed with pJF0333, cells gained back the methylation of ribonucleotide G2445 as shown by the stop of reverse transcription on the $23 \mathrm{~S}$ rRNA template (Fig. 3, lane 3).

The regain of methylation at position G2445 in 1974M1 was associated with an increased susceptibility to linezolid, but also to other antibiotics (Table 3). As susceptibility testing is simpler than primer extension, we also transformed pJF0333 in R6M1 (which had a 7-bp deletion in the spr0333 gene), and these cells were also shown to be more susceptible to linezolid (Table 3 ). The R6M2 with a C208Y mutation and 1974M2 with a G209V mutation in the spr0333 protein were also more susceptible to linezolid when these cells were transformed with pJF0333 (results not shown), demonstrating that different mutations in spr0333 are directly linked to linezolid resistance. Mutations in spr0333 were a relatively late event, being detected in cells resistant to either 16

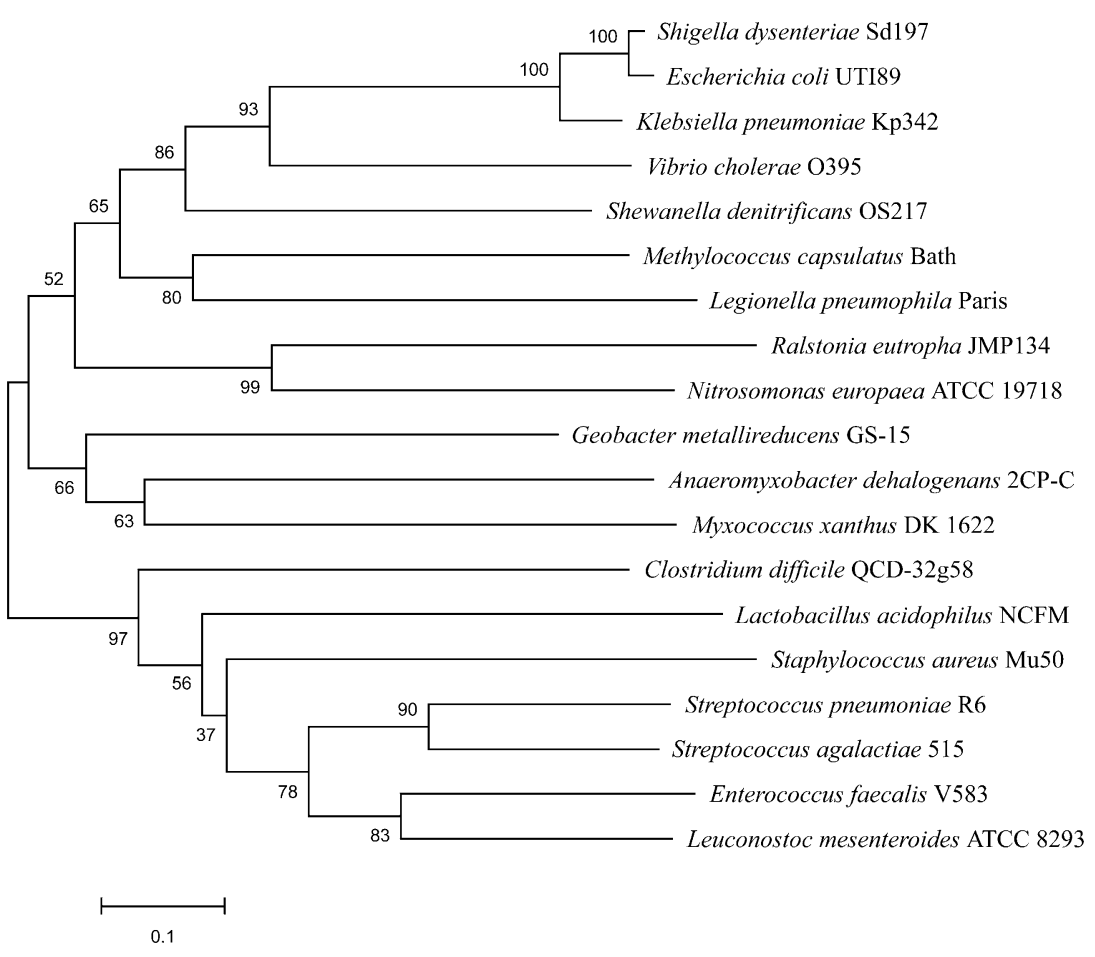

Figure 2. Phylogenetic analysis of a class of RNA methyltransferases related to spr0333. Amino acid sequences of the RNA methyltransferase proteins were aligned using the ClustalW algorithm, and evolutionary trees were constructed using the Neighbor-Joining method with Poisson correction as implemented in the MEGA3.1 package for the most conserved part of the proteins. The reliabilities of each branch point were assessed by the analysis of 1000 bootstrap replicates. A similar tree was obtained also when the whole protein was used for carrying the phylogenetic analysis (not shown).

\section{Genome Research www.genome.org}


A

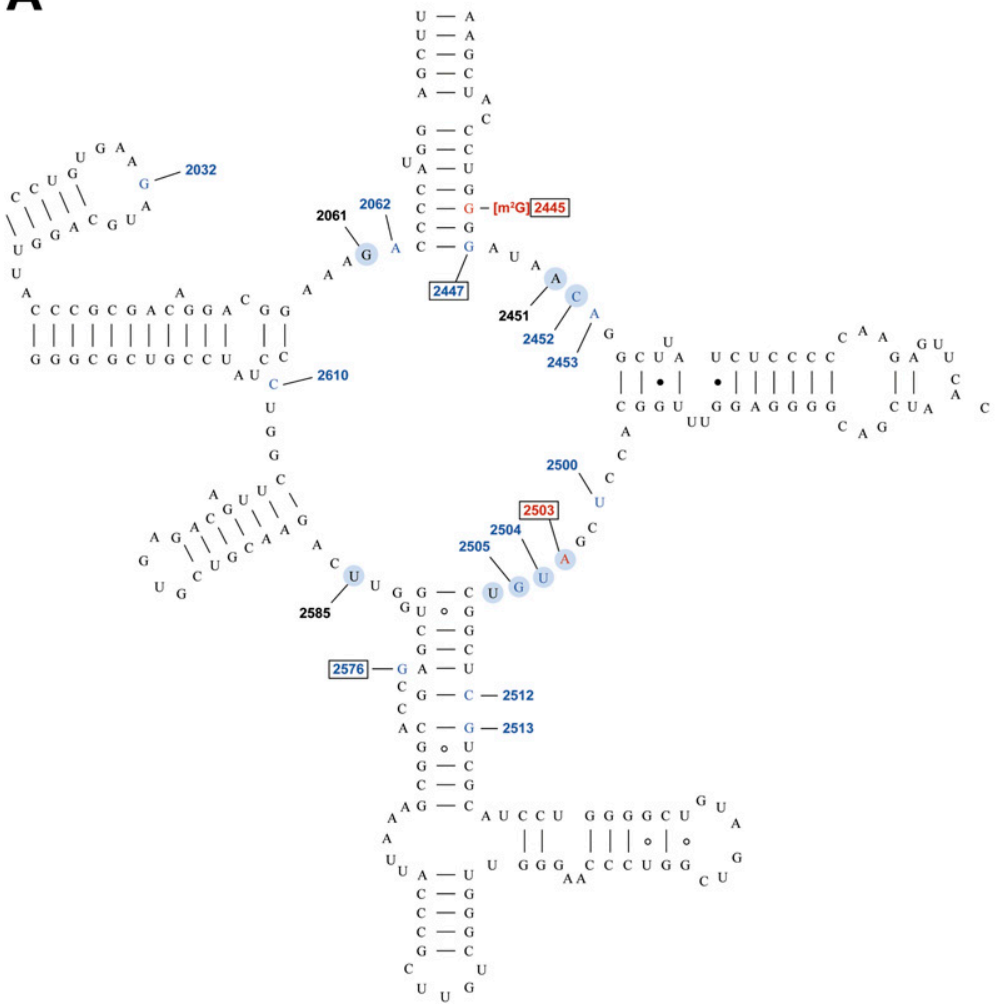

B
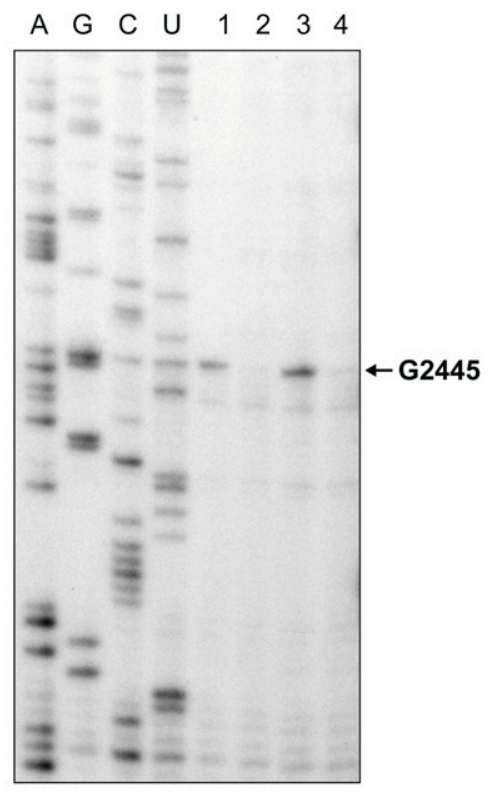

Figure 3. Mutations and modifications in the $23 \mathrm{~S}$ rRNA related to linezolid resistance. (A) Secondary-structure model of part of the $V$ domain of the $23 \mathrm{~S}$ rRNA of S. pneumoniae. (Blue) Mutations in the 23S rRNA linked to linezolid resistance; (boxed residues) positions 2445, 2447, 2503, and 2576 found in this study; (red) new mutations or resistance mechanisms; (shaded) nucleotides that directly interact with linezolid as determined from several structural studies cited in the text. (B) Reverse transcription analysis of the S. pneumoniae 23S rRNA. U, A, C, G correspond with sequencing lanes. Primer extension results of the 23S rRNA from the control susceptible strain 1974 (lane 1), 1974M1 (lane 2), 1974M1 with pJF0333 (lane 3), $1974 \mathrm{M} 1$ with vector pDL289 (lane 4) are shown. The block (when present) in the reverse transcription reaction at position G2445 is indicated.

or $32 \mu \mathrm{g} / \mathrm{mL}$ linezolid (Supplemental Table 2), suggesting that this mutation may occur after other mutations such as in the $23 \mathrm{~S}$ rRNA. Consistent with this hypothesis, we did not observe a change in susceptibility when the spr0333 gene was inactivated in wild-type cells (Table 3).

\section{Mutations in a chromosomally encoded RNA methylase and clinical resistance to linezolid}

The complete genome sequencing of several isolates has pinpointed a novel linezolid resistance marker. There are few if any reports of $S$. pneumoniae linezolid-resistant isolates, but there have been reports of linezolid-resistant staphylococci and enterococci.
The staphylococci and the enterococci have a spr0333 ortholog (Fig. 2). In the NARSA collection (www.narsa.net) of vancomycinintermediate MRSA (VISA) that we have studied in the past (Drummelsmith et al. 2007), we confirmed that three isolates, NRS 119,127 , and 271, were linezolid-resistant (Table 4). Sequencing of the $\mathrm{V}$ region of the 23S rRNA gene of these isolates indicated the mutation G2576T in both NRS271 and NRS119, but a G2447T mutation for NRS127 (Table 4). The spr0333 ortholog in S. aureus is SAV1444 (nomenclature of $S$. aureus Mu50) (Kuroda et al. 2001), and it shares $\sim 45 \%$ identity with the $S$. pneumoniae ortholog. In the isolate NRS119, which had the highest MIC against linezolid, the sequence of the SAV1444 gene revealed a 39-bp deletion in the SAM-methylation domain (Table 4). No mutations were observed

Table 4. Mutations in linezolid-resistant Staphylococcus aureus clinical isolates

\begin{tabular}{|c|c|c|c|c|}
\hline $\begin{array}{l}\text { Staphylococcus aureus } \\
\text { strains }\end{array}$ & $\begin{array}{l}\text { Linezolid MIC } \\
\quad(\mu \mathrm{g} / \mathrm{mL})\end{array}$ & $\begin{array}{c}\text { Multilocus sequence } \\
\text { type }\end{array}$ & $\begin{array}{l}\text { Mutations in SAV1444 } \\
\text { (homolog of spr0333) }\end{array}$ & $\begin{array}{l}\text { Mutation in } \\
235 \text { rDNA }\end{array}$ \\
\hline \multicolumn{5}{|l|}{ Clinical isolates } \\
\hline NRS127 & 1.5 & ST5 & No mutation & G2447T \\
\hline NRS271 & 14 & ST22 & No mutation & $\mathrm{G} 2576 \mathrm{~T}^{\mathrm{a}}$ \\
\hline NRS119 & 48 & ST507 & 39-bp deletion (931-969) & $\mathrm{G} 2576 \mathrm{~T}^{\mathrm{a}}$ \\
\hline \multicolumn{5}{|c|}{ Resistant mutants selected in vitro } \\
\hline NRS127M1 & 128 & ST5 & No mutation & G2447T \\
\hline NRS271M1 & 256 & ST22 & 60-bp deletion (775-834) & $\mathrm{G} 2576 \mathrm{~T}^{\mathrm{a}}$ \\
\hline
\end{tabular}

${ }^{\mathrm{a}}$ These mutations were also reported by Tsiodras et al. (2001) and Wilson et al. (2003). 
in the two other VISA isolates that were less resistant to linezolid. NRS271 and NRS127 were selected in vitro for increased linezolid resistance, and their SAV1444 gene was resequenced. A 60-bp deletion was observed in the in vitro linezolid-selected NRS271 (Table 4).

\section{Discussion}

Complete bacterial genome sequencing is emerging as a costeffective approach for identifying candidate genes and determining the mode of action and resistance to drugs (Albert et al. 2005; Andries et al. 2005; Fournier et al. 2006; Manjunatha et al. 2006; Mwangi et al. 2007; Howden et al. 2008). We used wholegenome sequencing of linezolid-resistant $S$. pneumoniae strains to find novel resistance mutations. Our strategy was based on sequencing several isolates selected for resistance in vitro. In vitro selected isolates were studied because (1) S. pneumoniae linezolidresistant clinical isolates are not yet available; (2) the polymorphism between field isolates is such that it would be difficult to discriminate between resistance mutations and natural polymorphisms; (3) resistance to linezolid has been shown so far to be due mostly to point mutations that were shared between in vitro selected organisms and clinical isolates. Linezolid is a novel class of antibiotics to which resistance has only recently been described and involves primarily mutations in the 23S rRNA gene and most notably the mutation G2576T (for review, see Meka and Gold 2004). Indeed, this mutation was found in three out of the four $S$. pneumoniae (Table 2) and two out of three S. aureus (Table 4) strains resistant to linezolid. Resistant cells not having this key mutation usually have other mutations in the $23 \mathrm{~S}$ rRNA gene (Fig. $3 \mathrm{~A}$ ), and this was also found to be the case for 1974M2 (Table 2) or NRS127 (Table 4). Mutation G2447T was previously linked to linezolid resistance (Xiong et al. 2000). The mutations A2503G and A1743T in 1974M2 are associated with linezolid resistance for the first time. A recent crystal structure of linezolid bound to the $50 \mathrm{~S}$ ribosomal subunit has shown interaction between the antibiotic and A2503 (Leach et al. 2007; Ippolito et al. 2008; Wilson et al. 2008), and mutation of this residue was observed in some chloramphenicol-resistant mutants (Gregory et al. 2005). Interestingly, methylation of the $\mathrm{A} 2503$ residue by the acquired cfr gene also led to linezolid resistance (Toh et al. 2007). Mutation at G2447 was also correlated with resistance to several antibiotics, including chloramphenicol (Gregory et al. 2005), tiamulin (Pringle et al. 2004), and anisomycin (Blaha et al. 2008) in addition to linezolid (this study) (Xiong et al. 2000). The A1743 residue is not in the $\mathrm{V}$ region of the 23S rRNA, and further work would be required to test whether it is involved in linezolid resistance.

The sequencing of several independent mutants from genetically different backgrounds has allowed the identification of independently recurring mutations. We hypothesized that recurrent mutations in independent mutants increase the likelihood that a particular gene is involved in resistance. In addition to the 23S rRNA, few mutations were common to at least two independent mutants. ABC proteins are involved in multidrug resistance in several microbial eukaryotic pathogens (Ouellette and Légaré 2002), but also in bacteria (Lubelski et al. 2007), and mutations within putative promoter regions of operons coding for $\mathrm{ABC}$ proteins were observed in more than one mutant (Fig. 1).

S. pneumoniae encodes $14 \mathrm{ABC}$ proteins, and disruption of 13 of them was possible. However, the disruption of only two $A B C$ genes, spr1887 (patA) and spr1885 (patB), was shown to lead to more susceptible bacteria (Robertson et al. 2005). The expression of these two genes was also shown to be up-regulated in cells treated with fluoroquinolones (Marrer et al. 2006a). The spr1887 and spr1885 proteins are the closest homologs of the well-studied multidrug-resistant proteins $\mathrm{LmrC}$ and $\mathrm{LmrD}$ of Lactococcus lactis (Lubelski et al. 2007). The increased expression of their genes in linezolid-resistant mutants (Fig. 1) indicated a direct involvement in linezolid resistance. Our gene disruption experiments of resistant cells provided evidence that PatA and PatB are associated with resistance to linezolid, although their role seems to be minor (Table 3). It has been suggested that they form heterodimers (Lubelski et al. 2007), and inactivation of both genes in the same cell may lead to further resistance. In addition to their role in linezolid resistance, analysis of the phenotype of either patA or pat $B$ disruptants clearly implicate the two $A B C$ proteins in a multidrug resistance phenotype due to increased RNA expression (Fig. 1; Table 3).

Inactivation of spr1021 in a wild-type context did not lead to decreased susceptibility to drugs (Table 3 ), confirming the results of others (Robertson et al. 2005). However, the disruption of the same ABC gene in the linezolid-resistant background 1974M2 led to increased susceptibility to linezolid and also to chloramphenicol and florfenicol (Table 3). Since the expression of the mutated gene was increased by sevenfold, inactivation of the gene may explain the gain in sensitivity of the mutant. Indeed, a similar observation was noted for the major facilitator efflux pump PmrA in S. pneumoniae, where inactivation in wild-type cells did not increase susceptibility (Robertson et al. 2005) but did render resistant cells more susceptible to drugs (Gill et al. 1999). Alternatively, mutations in primary targets (23S rRNA) may lead to an increased concentration of free unbound linezolid that needs to be extruded by an efflux system. Disruption of the latter system would lead to the decreased resistance as observed (Table 3). The work highlights how mutations in putative promoter regions can increase the expression of efflux pumps (PatA, PatB, spr1021), hence contributing to resistance to clinically useful drugs including linezolid.

In addition to describing a novel role for $\mathrm{ABC}$ proteins in linezolid resistance, our complete genome sequencing approach has led to the identification of a novel resistance mechanism and to finding a cellular function for a hypothetical protein of $S$. pneumoniae. The spr0333 protein corresponds to an rRNA methyltransferase modifying the G2445 residue. This protein is only distantly related to the RlmL (YcbY) protein of E. coli (Fig. 2), which modifies the G2445 residue of the 23S rRNA in E. coli (Lesnyak et al. 2006). Inactivation of the rlmL gene in E. coli did not lead to changes in drug susceptibilities including linezolid (Toh and Mankin 2008), and, similarly, inactivation of spr0333 in susceptible $S$. pneumoniae R6 also did not change resistance to linezolid (Table 3 ). However, in all $S$. pneumoniae cells highly resistant to linezolid, spr0333 was mutated (Table 2), and this was even seen in one $S$. aureus clinical isolate (Table 4). The role of spr0333 in 23S rRNA methylation was tested experimentally (Fig. $3)$. Transformation of spr0333 in resistant cells rescued the methylation defect at position G2445 and restored susceptibility to linezolid but also to other antibiotics (Table 3). Thus, the loss of methylation is clearly involved in resistance but first requires other mutations, most likely in the $23 \mathrm{~S}$ rRNA (e.g., position G2576T). Indeed, mutation in spr0333 occurred late during the selection process (Supplemental Table 2), and we propose a hierarchy in mutation selection. It is possible that some specific mutations would be required before the methylation status at position 2445 would be implicated in linezolid resistance. Indeed,

\section{Genome Research}


it was intriguing that we could not detect a mutation in spr0333 while selecting for increased resistance in S. aureus NRS127, which had another mutation close to position 2445 in the 23S rRNA (G2447) (Table 4). This would suggest the possibility of additional resistance mechanisms.

While we concentrated on recurrent mutations, the sequence analysis has revealed other strain-specific mutations, several of which could also contribute to resistance to linezolid. They are certainly worth investigating in additional studies, but it is possible that some of these mutations, despite further experimentation, may not be directly involved in the resistance phenotype. Two sequencing techniques were used in this study: microarray hybridizations and massively parallel DNA sequencing (MPS). Although we used a 454 Life Sciences (Roche) system, and other technologies are available (Illumina GAII and ABI SOLiD), de novo sequencing is still a sizable investment; however, costs are decreasing and it is becoming a routine technique (Kahvejian et al. 2008). Resequencing (microarray-based or low-coverage MPS) is less expensive, but the requirement of a prior reference sequence limits the species that can be analyzed. However, with improved bioinformatic tools and increasingly longer read lengths, including paired ends, it will likely become routine also to sequence de novo bacterial isolates using MPS short-read systems (Hernandez et al. 2008; Holt et al. 2008). This cost-effective de novo sequencing will allow the sequencing of clinical isolates. While several natural polymorphisms would be detected (Joyce et al. 2002), recurrence of a mutation in independent clinical isolates would provide a strong argument to pursue the more labor-intensive biological validation. This could prevent one of the main limitations in our current approach that requires a sequenced parent strain. These approaches are already leading to novel factors or concepts in bacterial virulence (Fouts et al. 2005; Gill et al. 2005; Highlander et al. 2007; Holt et al. 2008; Kennedy et al. 2008) and as suggested (Fournier et al. 2007; Francois et al. 2007; Kahvejian et al. 2008) will certainly contribute to a better understanding of the mutations and adaptations required to develop and maintain resistance. This study and other ongoing studies in the laboratory are certainly in agreement with the premise that whole-genome sequencing will be useful for understanding resistance mechanisms.

\section{Methods}

\section{Bacterial strains, growth conditions, and MIC determinations}

Key strains are listed in Supplemental Table 1. S. pneumoniae R6, whose genome sequence has been determined (Hoskins et al. 2001), and one clinical isolate, S. pneumoniae CCRI 1974, were chosen for the laboratory-induced development of resistance to linezolid. Pneumococci were grown in brain heart infusion broth (BHI, Difco) supplemented with $0.5 \%$ yeast extract, or in blood agar containing 5\% defibrinated sheep's blood as described previously (Munoz et al. 1992). Cultures were incubated for 16-24 h in a $5 \% \mathrm{CO}_{2}$ atmosphere at $37^{\circ} \mathrm{C}$. In order to select resistant cells, we subcultured R6 or CCRI 1974 in medium containing increasing concentration gradients of linezolid as described previously for other antibiotics (Martineau et al. 2000; Soualhine et al. 2005). Mutants were selected in a stepwise fashion by picking colonies growing at the highest antibiotic concentration at each stage. Six selection cycles were required to obtain two resistant mutants (M1 and M2) for each strain of S. pneumoniae. Minimal inhibitory concentration (MIC) to linezolid was determined by the E-test or the macrodilution method according to the guidelines of the
Clinical and Laboratory Standards Institute (CLSI). For the E-test, colonies from a fresh overnight plate were resuspended in phosphate saline buffer (PBS) to 0.5 McFarland units. The suspension was layered on Mueller-Hinton agar plates and then overlaid with E-test strips (AB Biodisk). For macrodilution, cation-adjusted Mueller-Hinton broth with lysed horse blood containing twofold concentration increments of linezolid was inoculated with a $5 \times$ $10^{5} \mathrm{cfu} / \mathrm{mL}$ bacterial suspension. The MIC was recorded as the lowest dilution showing no growth. All measurements were done at least in triplicate after 12-16 h of incubation, depending on the strain.

\section{Multilocus sequence typing (MLST)}

The MLST analysis was performed as described at http:// www.mlst.net. The aroE, gdh, gki, recP, spi, xpt, and $d d l$ genes for the $S$. pneumoniae strains and the arcC, aroE, glpF, gmk, pta, tpi, and $y q i L$ genes for the $S$. aureus strains were PCR amplified and sequenced. The sequence type (ST) of strains was obtained from the MLST database on the basis of the resulting allelic profile.

\section{Whole-genome sequencing}

Genomic DNAs were prepared from mid-log phase cultures of $S$. pneumoniae strains using the Wizard Genomic DNA Purification Kit (Promega) according to the manufacturer's instructions. Mutants R6M1 and R6M2 were sequenced using the NimbleGen whole-genome sequencing approach (http://www.nimblegen. com/). Briefly, DNA of each mutant isolate and the DNA of the progenitor isolate (which were differentially labeled with fluorescent markers) were co-hybridized on DNA tiling microarrays. Regions hybridizing differently were sequenced by a second round of sequencing hybridization arrays. The sequencing of both mutants and their analyses were performed by NimbleGen (Albert et al. 2005). The CCRI 1974 wild-type strain and the CCRI 1974 M2 mutant were sequenced by the massively parallel sequencing using the 454 Life Sciences (Roche) GS-FLX system. Genome sequencing, assemblies, and comparative analyses were performed at the McGill University and Génome Québec Innovation Center. The draft genome assemblies for CCRI 1974 and CCRI 1974 M2 have been submitted to NCBI/DDBJ/EMBL/ GenBank under the project accession numbers ABZC00000000 and ABZT00000000. The versions described in this study are the first versions, ABZC01000000 and ABZT01000000. The CCRI 1974 shotgun sequencing led to an assembly of 121 contigs with an aggregate genome size of 2,000,683 bp. The 1974M2 isolate sequencing project produced an assembly of similar quality (130 contigs, $1,998,515 \mathrm{bp}$ ). Whenever possible, the order and orientation of assembled contigs was done in accordance with the genome assembly of the $S$. pneumoniae TIGR4 isolate (accession number NC_003028). Mutations, deduced either from array hybridizations or massively parallel sequencing, were confirmed by PCR amplification and conventional DNA sequencing. The primers were designed on the basis of the published $S$. pneumoniae TIGR4 strain (Tettelin et al. 2001). Specific primers targeting the four individual $23 \mathrm{~S}$ rRNA genes were designed.

\section{RNA isolation and qRT-PCR}

Wild-type and linezolid-resistant mutant S. pneumoniae strains were grown in BHI in the absence of antibiotics. Bacterial cells were harvested for RNA isolation during the logarithmic growth phase at an $\mathrm{OD}_{600 \mathrm{~nm}}$ of 0.35-0.45. Total RNAs from sensitive and resistant derivatives were isolated using the Qiagen RNeasy Mini 
Kit (Qiagen) according to the manufacturer's instructions. Contaminating DNA was digested with DNase I (Ambion). The quality and integrity of the starting RNA material were assessed with an Agilent Technologies 2100 BioAnalyzer using the RNA 6000 Nano LabChIP kit (Agilent). The cDNAs were generated from total RNAs using a random hexamer primer following the protocol for Superscript II (Invitrogen). Real-time quantitative RT-PCR assays were carried out in a BioRad Cycler using SYBR Green I (Molecular Probes). The reactions were carried out in a final volume of $20 \mu \mathrm{L}$ containing specific primers, and iQ SYBR Green Supermix (BioRad). All real-time RT-PCR data were normalized with the real-time amplification of the $16 \mathrm{~S}$ rRNA. The expression data are shown relative to the data for the wild-type strain.

\section{DNA constructs}

The genetic constructs used in this study are described in Supplemental Table 1. Gene inactivation was done by insertional duplication mutagenesis using the nonreplicative plasmid pFF6, a pGEMT Easy (Promega) derivative where the ampicillin resistance marker was replaced by the kanamycin resistance gene marker of pDL289 (Buckley et al. 1995), which is expressed through the amiC promoter (F Fani, J Feng, and M Ouellette, unpubl.). PCR fragments of the selected genes were derived from strain S. pneumoniae R6 or CCRI 1974 and cloned into the multiple cloning sites of pFF6. For episomal expression, the entire coding sequences of genes of interest were PCR amplified with primers containing BamHI and XbaI and cloned into the S. pneumoniae-E. coli shuttle vector pDL289 (Buckley et al. 1995), a kind gift of D. Cvitkovitch (University of Toronto). The plasmid DNAs $(2 \mu \mathrm{g})$ were introduced in $S$. pneumoniae in which competence was induced using a competence peptide as described (Soualhine et al. 2005). Transformants were selected in media containing $500 \mu \mathrm{g} /$ $\mathrm{mL}$ kanamycin. Proper integration leading to gene inactivation was confirmed by PCR.

\section{Primer extension analysis}

The primer ( $5^{\prime}$-TACAGCCCCAGGATGCGAC-3'), corresponding to the reverse complement of nucleotides $2512-2531$ of $S$. pneumoniae $23 \mathrm{~S}$ rRNA, was $\left[5^{\prime}-{ }^{32} \mathrm{P}\right]$-labeled. Total $S$. pneumoniae RNA (1 $\mu \mathrm{g})$ and the labeled primer were annealed by heating the tubes at $60^{\circ} \mathrm{C}$ followed by cooling for $10 \mathrm{~min}$ at room temperature. The AMV reverse transcriptase (Promega) was added and incubated for $30 \mathrm{~min}$ at $42^{\circ} \mathrm{C}$. The cDNA products of the primer extension reactions were separated on $8 \%$ polyacrylamide sequencing gels. The gels were transferred to Whatman paper, dried, and revealed using autoradiography.

\section{Acknowledgments}

We thank Gary Leveque, Corina Nagy, and Joana Dias from the McGill University and Genome Quebec Innovation Centre for performing the sequencing and Vince Forgetta for submitting the genome assemblies to the public databases. We thank Dr. Maurice Boissinot for strain CCRI 1974. Clinical VISA isolates were obtained through the Network on Antimicrobial Resistance in S. aureus (NARSA) Program, supported under NIAID/NIH Contract No. N01-AI-95359. This work was funded by a CIHR grant to M.O. J.F. is a Strategic Training Fellow of the Strategic Training Program in Microbial Resistance, a partnership of the CIHR Institute of Infection and Immunity and the Fonds de Recherche en Sante du Québec. M.O. is a Burroughs Wellcome Fund Scholar in Molecular Parasitology and holds the Canada Research Chair in Antimicrobial Resistance.

\section{References}

Albert TJ, Dailidiene D, Dailide G, Norton JE, Kalia A, Richmond TA, Molla M, Singh J, Green RD, Berg DE. 2005. Mutation discovery in bacterial genomes: Metronidazole resistance in Helicobacter pylori. Nat Methods 2: 951-953.

Andries K, Verhasselt P, Guillemont J, Gohlmann HW, Neefs JM, Winkler H, Van Gestel J, Timmerman P, Zhu M, Lee E, et al. 2005. A diarylquinoline drug active on the ATP synthase of Mycobacterium tuberculosis. Science 307: 223-227.

Besier S, Ludwig A, Zander J, Brade V, Wichelhaus TA. 2008. Linezolid resistance in Staphylococcus aureus: Gene dosage effect, stability, fitness costs, and cross-resistances. Antimicrob Agents Chemother 52: 1570-1572.

Blaha G, Gurel G, Schroeder SJ, Moore PB, Steitz TA. 2008. Mutations outside the anisomycin-binding site can make ribosomes drug-resistant. J Mol Biol 379: 505-519.

Bourgeois-Nicolaos N, Massias L, Couson B, Butel MJ, Andremont A, Doucet-Populaire F. 2007. Dose dependence of emergence of resistance to linezolid in Enterococcus faecalis in vivo. J Infect Dis 195: 1480-1488.

Buckley ND, Lee LN, LeBlanc DJ. 1995. Use of a novel mobilizable vector to inactivate the scrA gene of Streptococcus sobrinus by allelic replacement. $J$ Bacteriol 177: 5028-5034.

Carsenti-Dellamonica H, Galimand M, Vandenbos F, Pradier C, Roger PM, Dunais B, Sabah M, Mancini G, Dellamonica P. 2005. In vitro selection of mutants of Streptococcus pneumoniae resistant to macrolides and linezolid: Relationship with susceptibility to penicillin $\mathrm{G}$ or macrolides. J Antimicrob Chemother 56: 633-642.

Drummelsmith J, Winstall E, Bergeron MG, Poirier GG, Ouellette M. 2007 Comparative proteomics analyses reveal a potential biomarker for the detection of vancomycin-intermediate Staphylococcus aureus strains. J Proteome Res 6: 4690-4702.

Fournier PE, Vallenet D, Barbe V, Audic S, Ogata H, Poirel L, Richet H, Robert C, Mangenot S, Abergel C, et al. 2006. Comparative genomics of multidrug resistance in Acinetobacter baumannii. PLoS Genet 2: e7. doi: 10.1371/journal.pgen.0020007.

Fournier PE, Drancourt M, Raoult D. 2007. Bacterial genome sequencing and its use in infectious diseases. Lancet Infect Dis 7: 711-723.

Fouts DE, Mongodin EF, Mandrell RE, Miller WG, Rasko DA, Ravel J, Brinkac LM, DeBoy RT, Parker CT, Daugherty SC, et al. 2005. Major structural differences and novel potential virulence mechanisms from the genomes of multiple Campylobacter species. PLoS Biol 3: e15. doi: 10.1371/journal.pbio.0030015.

Francois P, Hernandez D, Schrenzel J. 2007. Genome content determination in methicillin-resistant Staphylococcus aureus. Future Microbiol 2: 187-198.

Gill MJ, Brenwald NP, Wise R. 1999. Identification of an efflux pump gene, pmrA, associated with fluoroquinolone resistance in Streptococcus pneumoniae. Antimicrob Agents Chemother 43: 187-189.

Gill SR, Fouts DE, Archer GL, Mongodin EF, Deboy RT, Ravel J, Paulsen IT, Kolonay JF, Brinkac L, Beanan M, et al. 2005. Insights on evolution of virulence and resistance from the complete genome analysis of an early methicillin-resistant Staphylococcus aureus strain and a biofilmproducing methicillin-resistant Staphylococcus epidermidis strain. J Bacteriol 187: 2426-2438.

Gonzales RD, Schreckenberger PC, Graham MB, Kelkar S, DenBesten K, Quinn JP. 2001. Infections due to vancomycin-resistant Enterococcus faecium resistant to linezolid. Lancet 357: 1179.

Gregory ST, Carr JF, Rodriguez-Correa D, Dahlberg AE. 2005. Mutational analysis of $16 \mathrm{~S}$ and $23 \mathrm{~S}$ rRNA genes of Thermus thermophilus. J Bacteriol 187: 4804-4812.

Hernandez D, Francois P, Farinelli L, Osteras M, Schrenzel J. 2008. De novo bacterial genome sequencing: Millions of very short reads assembled on a desktop computer. Genome Res 18: 802-809.

Highlander SK, Hulten KG, Qin X, Jiang H, Yerrapragada S, Mason EO Jr, Shang Y, Williams TM, Fortunov RM, Liu Y, et al. 2007. Subtle genetic changes enhance virulence of methicillin resistant and sensitive Staphylococcus aureus. BMC Microbiol 7: 99. doi: 10.1186/1471-2180-7-99.

Hiller NL, Janto B, Hogg JS, Boissy R, Yu S, Powell E, Keefe R, Ehrlich NE, Shen K, Hayes J, et al. 2007. Comparative genomic analyses of seventeen Streptococcus pneumoniae strains: Insights into the pneumococcal supragenome. J Bacteriol 189: 8186-8195.

Holt KE, Parkhill J, Mazzoni CJ, Roumagnac P, Weill FX, Goodhead I, Rance R, Baker S, Maskell DJ, Wain J, et al. 2008. High-throughput sequencing provides insights into genome variation and evolution in Salmonella typhi. Nat Genet 40: 987-993.

Hong T, Li X, Wang J, Sloan C, Cicogna C. 2007. Sequential linezolidresistant Staphylococcus epidermidis isolates with G2576T mutation. J Clin Microbiol 45: 3277-3280.

Hoskins J, Alborn WE Jr, Arnold J, Blaszczak LC, Burgett S, DeHoff BS, Estrem ST, Fritz L, Fu DJ, Fuller W, et al. 2001. Genome of the bacterium Streptococcus pneumoniae strain R6. J Bacteriol 183: 5709-5717.

\section{Genome Research}


Howden BP, Stinear TP, Allen DL, Johnson PD, Ward PB, Davies JK. 2008. Genomic analysis reveals a point mutation in the two-component sensor gene graS that leads to intermediate vancomycin resistance in clinical Staphylococcus aureus. Antimicrob Agents Chemother 52: 3755-3762.

Ippolito JA, Kanyo ZF, Wang D, Franceschi FJ, Moore PB, Steitz TA, Duffy EM. 2008. Crystal structure of the oxazolidinone antibiotic linezolid bound to the 50S ribosomal subunit. J Med Chem 51: 3353-3356.

Jones RN, Fritsche TR, Sader HS, Ross JE. 2007. Zyvox annual appraisal of potency and spectrum program results for 2006: An activity and spectrum analysis of linezolid using clinical isolates from 16 countries. Diagn Microbiol Infect Dis 59: 199-209.

Joyce EA, Chan K, Salama NR, Falkow S. 2002. Redefining bacterial populations: A post-genomic reformation. Nat Rev Genet 3: 462-473.

Kahvejian A, Quackenbush J, Thompson JF. 2008. What would you do if you could sequence everything? Nat Biotechnol 26: 1125-1133.

Kelly S, Collins J, Maguire M, Gowing C, Flanagan M, Donnelly M, Murphy PG. 2008. An outbreak of colonization with linezolid-resistant Staphylococcus epidermidis in an intensive therapy unit. J Antimicrob Chemother 61: 901-907.

Kennedy AD, Otto M, Braughton KR, Whitney AR, Chen L, Mathema B, Mediavilla JR, Byrne KA, Parkins LD, Tenover FC, et al. 2008. Epidemic community-associated methicillin-resistant Staphylococcus aureus: Recent clonal expansion and diversification. Proc Natl Acad Sci 105: 1327-1332.

Kuroda M, Ohta T, Uchiyama I, Baba T, Yuzawa H, Kobayashi I, Cui L, Oguchi A, Aoki K, Nagai Y, et al. 2001. Whole genome sequencing of meticillin-resistant Staphylococcus aureus. Lancet 357: 1225-1240.

Leach KL, Swaney SM, Colca JR, McDonald WG, Blinn JR, Thomasco LM, Gadwood RC, Shinabarger D, Xiong L, Mankin AS. 2007. The site of action of oxazolidinone antibiotics in living bacteria and in human mitochondria. Mol Cell 26: 393-402.

Lesnyak DV, Sergiev PV, Bogdanov AA, Dontsova OA. 2006. Identification of Escherichia coli $\mathrm{m} 2 \mathrm{G}$ methyltransferases: I. The $y c b Y$ gene encodes a methyltransferase specific for G2445 of the 23 S rRNA. J Mol Biol 364: 20-25.

Lubelski J, Konings WN, Driessen AJ. 2007. Distribution and physiology of ABC-type transporters contributing to multidrug resistance in bacteria. Microbiol Mol Biol Rev 71: 463-476.

Manjunatha UH, Boshoff H, Dowd CS, Zhang L, Albert TJ, Norton JE, Daniels L, Dick T, Pang SS, Barry CE III. 2006. Identification of a nitroimidazo-oxazine-specific protein involved in PA-824 resistance in Mycobacterium tuberculosis. Proc Natl Acad Sci 103: 431-436.

Marrer E, Satoh AT, Johnson MM, Piddock LJ, Page MG. 2006a. Global transcriptome analysis of the responses of a fluoroquinolone-resistant Streptococcus pneumoniae mutant and its parent to ciprofloxacin. Antimicrob Agents Chemother 50: 269-278.

Marrer E, Schad K, Satoh AT, Page MG, Johnson MM, Piddock LJ. 2006b. Involvement of the putative ATP-dependent efflux proteins PatA and PatB in fluoroquinolone resistance of a multidrug-resistant mutant of Streptococcus pneumoniae. Antimicrob Agents Chemother 50: 685-693.

Marshall SH, Donskey CJ, Hutton-Thomas R, Salata RA, Rice LB. 2002. Gene dosage and linezolid resistance in Enterococcus faecium and Enterococcus faecalis. Antimicrob Agents Chemother 46: 3334-3336.

Martineau F, Picard FJ, Lansac N, Menard C, Roy PH, Ouellette M, Bergeron MG. 2000. Correlation between the resistance genotype determined by multiplex PCR assays and the antibiotic susceptibility patterns of Staphylococcus aureus and Staphylococcus epidermidis. Antimicrob Agents Chemother 44: 231-238.

Meka VG, Gold HS. 2004. Antimicrobial resistance to linezolid. Clin Infect Dis 39: 1010-1015.

Meka VG, Pillai SK, Sakoulas G, Wennersten C, Venkataraman L, DeGirolami PC, Eliopoulos GM, Moellering RC Jr, Gold HS. 2004 Linezolid resistance in sequential Staphylococcus aureus isolates associated with a T2500A mutation in the 23S rRNA gene and loss of a single copy of rRNA. J Infect Dis 190: 311-317.

Mendes RE, Deshpande LM, Castanheira M, Dipersio J, Saubolle M, Jones RN. 2008. First report of $c f r$-mediated resistance to linezolid in human staphylococcal clinical isolates recovered in the United States. Antimicrob Agents Chemother 52: 2244-2246.

Munoz R, Dowson CG, Daniels M, Coffey TJ, Martin C, Hakenbeck R, Spratt BG. 1992. Genetics of resistance to third-generation cephalosporins in clinical isolates of Streptococcus pneumoniae. Mol Microbiol 6: 2461-2465.

Mutnick AH, Enne V, Jones RN. 2003. Linezolid resistance since 2001: SENTRY Antimicrobial Surveillance Program. Ann Pharmacother 37: 769-774.

Mwangi MM, Wu SW, Zhou Y, Sieradzki K, de Lencastre H, Richardson P, Bruce D, Rubin E, Myers E, Siggia ED, et al. 2007. Tracking the in vivo evolution of multidrug resistance in Staphylococcus aureus by wholegenome sequencing. Proc Natl Acad Sci 104: 9451-9456.

Ouellette M, Légaré D. 2002. Clinical relevance of drug resistance mediated by ABC-transporters in parasites of humans. In ABC transporters (eds. B. Holland et al.), pp. 317-333. Academic Press, New York.
Ouellette M, Legare D, Papadopoulou B. 1994. Microbial multidrugresistance ABC transporters. Trends Microbiol 2: 407-411.

Pringle M, Poehlsgaard J, Vester B, Long KS. 2004. Mutations in ribosomal protein L3 and 23S ribosomal RNA at the peptidyl transferase centre are associated with reduced susceptibility to tiamulin in Brachyspira spp. isolates. Mol Microbiol 54: 1295-1306.

Prystowsky J, Siddiqui F, Chosay J, Shinabarger DL, Millichap J, Peterson LR, Noskin GA. 2001. Resistance to linezolid: Characterization of mutations in rRNA and comparison of their occurrences in vancomycin-resistant enterococci. Antimicrob Agents Chemother 45: 2154-2156.

Richter E, Rusch-Gerdes S, Hillemann D. 2007. First linezolid-resistant clinical isolates of Mycobacterium tuberculosis. Antimicrob Agents Chemother 51: 1534-1536.

Roberts MC. 2008. Update on macrolide-lincosamide-streptogramin ketolide, and oxazolidinone resistance genes. FEMS Microbiol Lett 282: 147-159.

Robertson GT, Doyle TB, Lynch AS. 2005. Use of an efflux-deficient streptococcus pneumoniae strain panel to identify ABC-class multidrug transporters involved in intrinsic resistance to antimicrobial agents. Antimicrob Agents Chemother 49: 4781-4783.

Ruggero KA, Schroeder LK, Schreckenberger PC, Mankin AS, Quinn JP. 2003. Nosocomial superinfections due to linezolid-resistant Enterococcus faecalis: Evidence for a gene dosage effect on linezolid MICs. Diagn Microbiol Infect Dis 47: 511-513.

Sander P, Belova L, Kidan YG, Pfister P, Mankin AS, Bottger EC. 2002. Ribosomal and non-ribosomal resistance to oxazolidinones: Speciesspecific idiosyncrasy of ribosomal alterations. Mol Microbiol 46: 12951304.

Schlunzen F, Zarivach R, Harms J, Bashan A, Tocilj A, Albrecht R, Yonath A, Franceschi F. 2001. Structural basis for the interaction of antibiotics with the peptidyl transferase centre in eubacteria. Nature 413: 814-821.

Sinclair A, Arnold C, Woodford N. 2003. Rapid detection and estimation by pyrosequencing of $23 \mathrm{~S}$ rRNA genes with a single nucleotide polymorphism conferring linezolid resistance in Enterococci. Antimicrob Agents Chemother 47: 3620-3622.

Soualhine H, Brochu V, Menard F, Papadopoulou B, Weiss K, Bergeron MG, Legare D, Drummelsmith J, Ouellette M. 2005. A proteomic analysis of penicillin resistance in Streptococcus pneumoniae reveals a novel role for PstS, a subunit of the phosphate ABC transporter. Mol Microbiol 58: 1430-1440.

Tettelin H, Nelson KE, Paulsen IT, Eisen JA, Read TD, Peterson S, Heidelberg J, DeBoy RT, Haft DH, Dodson RJ, et al. 2001. Complete genome sequence of a virulent isolate of Streptococcus pneumoniae. Science 293: 498-506.

Thornsberry C, Brown NP, Draghi DC, Evangelista AT, Yee YC, Sahm DF 2008. Antimicrobial activity among multidrug-resistant Streptococcus pneumoniae isolated in the United States, 2001-2005. Postgrad Med 120: 32-38.

Toh SM, Mankin AS. 2008. An indigenous posttranscriptional modification in the ribosomal peptidyl transferase center confers resistance to an array of protein synthesis inhibitors. J Mol Biol 380: 593-597.

Toh SM, Xiong L, Arias CA, Villegas MV, Lolans K, Quinn J, Mankin AS. 2007. Acquisition of a natural resistance gene renders a clinical strain of methicillin-resistant Staphylococcus aureus resistant to the synthetic antibiotic linezolid. Mol Microbiol 64: 1506-1514.

Tsakris A, Pillai SK, Gold HS, Thauvin-Eliopoulos C, Venkataraman L, Wennersten C, Moellering RC Jr, Eliopoulos GM. 2007. Persistence of rRNA operon mutated copies and rapid re-emergence of linezolid resistance in Staphylococcus aureus. J Antimicrob Chemother 60: 649-651.

Tsiodras S, Gold HS, Sakoulas G, Eliopoulos GM, Wennersten C, Venkataraman L, Moellering RC, Ferraro MJ. 2001. Linezolid resistance in a clinical isolate of Staphylococcus aureus. Lancet 358: 207-208.

Vara Prasad JV. 2007. New oxazolidinones. Curr Opin Microbiol 10: 454-460.

Wilson DN, Schluenzen F, Harms JM, Starosta AL, Connell SR, Fucini P. 2008. The oxazolidinone antibiotics perturb the ribosomal peptidyltransferase center and effect tRNA positioning. Proc Natl Acad Sci 105: 13339-13344.

Wilson P, Andrews JA, Charlesworth R, Walesby R, Singer M, Farrell DJ, Robbins M. 2003. Linezolid resistance in clinical isolates of Staphylococcus aureus. J Antimicrob Chemother 51: 186-188.

Wolter N, Smith AM, Farrell DJ, Schaffner W, Moore M, Whitney CG, Jorgensen JH, Klugman KP. 2005. Novel mechanism of resistance to oxazolidinones, macrolides, and chloramphenicol in ribosomal protein L4 of the pneumococcus. Antimicrob Agents Chemother 49: 3554-3557.

Xiong L, Kloss P, Douthwaite S, Andersen NM, Swaney S, Shinabarger DL, Mankin AS. 2000. Oxazolidinone resistance mutations in 23S rRNA of Escherichia coli reveal the central region of domain $\mathrm{V}$ as the primary site of drug action. J Bacteriol 182: 5325-5331.

Received November 20, 2008; accepted in revised form April 2, 2009. 


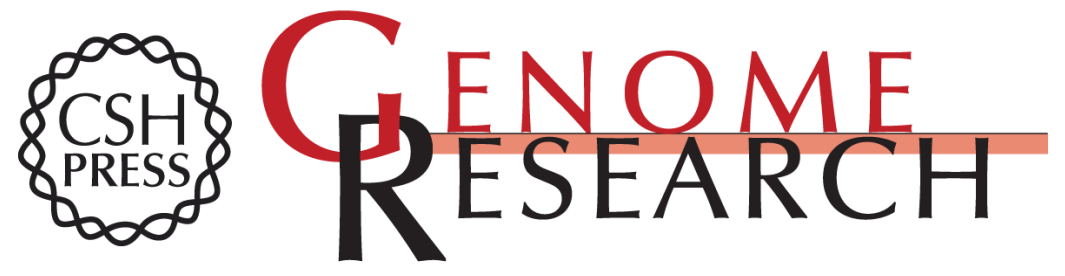

\section{Genome sequencing of linezolid-resistant Streptococcus pneumoniae mutants reveals novel mechanisms of resistance}

Jie Feng, Andréanne Lupien, Hélène Gingras, et al.

Genome Res. 2009 19: 1214-1223 originally published online April 6, 2009

Access the most recent version at doi:10.1101/gr.089342.108

Supplemental Material

References

License

Email Alerting Service
http://genome.cshlp.org/content/suppl/2009/05/15/gr.089342.108.DC1

This article cites 66 articles, 28 of which can be accessed free at: http://genome.cshlp.org/content/19/7/1214.full.html\#ref-list-1

Receive free email alerts when new articles cite this article - sign up in the box at the top right corner of the article or click here.

\section{Affordable, Accurate Sequencing.}

To subscribe to Genome Research go to:

https://genome.cshlp.org/subscriptions 